Northern analysis and reverse transcription. Purification of poly $(\mathrm{A})^{+}$ mRNA, and northern blot hybridization were performed essentially as described $^{22}$. To assess the induction of SOCS genes by IL-6, mice (C57BL/6) were injected intravenously with $5 \mu \mathrm{g}$ IL- 6 followed by collection of the liver at the indicated timepoints after injection. M1 cells were cultured in the presence of $20 \mathrm{ng} \mathrm{ml}^{-1}$ IL- 6 and collected at the indicated times. For RT-PCR analysis, bone marrow cells were collected as described ${ }^{23}$ and stimulated for $1 \mathrm{~h}$ at $37^{\circ} \mathrm{C}$ with $100 \mathrm{ng} \mathrm{ml}^{-1}$ of a range of cytokines. RT-PCR was performed on total RNA as described ${ }^{23}$. PCR products were resolved on an agarose gel and Southern blots were hybridized as described ${ }^{23}$ with probes specific for each SOCS family member. Expression of $\beta$-actin was assessed to ensure uniformity of amplification.

Western blotting and electrophoretic mobility shift assays. M1 cells $\left(10^{7}\right)$ or their derivatives were stimulated for $4 \mathrm{~min}$ at $37^{\circ} \mathrm{C}$ with either saline or $100 \mathrm{ng} \mathrm{ml}^{-1}$ IL-6. Cells were lysed and 1 to $2 \mathrm{mg}$ protein was immunoprecipitated with $4 \mu \mathrm{g}$ anti-gp130 antibody (M20; Santa Cruz Biotechnology, Santa Cruz, CA) essentially as described ${ }^{24}$. Western blots were performed using antityrosine phosphorylated STAT3 or anti-STAT3 (New England Biolabs, Beverly, MA), or anti-gp130 (Santa Cruz Biotechnology) as described ${ }^{25}$. Electrophoretic mobility shift assays were performed using the m67 oligonucleotide probe, as described $^{26}$.

Received 19 December 1996; accepted 21 March 1997

1. Nicola, N. A. Guidebook to Cytokines and Their Receptors (Oxford Univ. Press, Oxford, 1994).

2. Ihle, J. N. Cytokine receptor signalling. Nature 377, 591-594 (1995).

3. Ihle, J. N., Witthuhn, B. A., Quelle, F. W., Yamamoto, K. \& Silvennoinen, O. Signaling through the hematopoietic cytokine receptors. Ann. Rev. Immunol. 13, 369-398 (1995).

4. Darnell, J. Jr, Kerr, I. M. \& Stark, G. R. Jak-STAT pathways and transcriptional activation in response to IFNs and other extracellular signaling proteins. Science 264, 1415-1421 (1994).

Yoshimura, A. et al. A novel cytokine-inducible gene CIS encodes an SH2-containing protein that binds to tyrosine-phosphorylated interleukin 3 and erythropoietin receptors. EMBO J. 14, 2816-2826 (1985).

6. Metcalf, D., Hilton, D. J. \& Nicola, N. A. Clonal analysis of the actions of the murine leukemia inhibitory factor on leukemic and normal murine hemopoietic cells. Leukemia 2, 216-221 (1988). Lotem, J., Shabo, Y. \& Sachs, L. Clonal variation in susceptibility to differentiation by different protein. Leukemia 3, 804-807 (1989)

8. Rayner, J. R. \& Gonda, T. J. A simple and efficient procedure for generating stable expression libraries by cDNA cloning in a retroviral vector. Mol. Cell. Biol. 14, 880-887 (1994).

9. Schlueter, G. et al. Sequence analysis of the conserved Protamine gene cluster shows that it contains a fourth expressed gene. Mol. Reprod. Dev. 43, 1-6 (1996).

10. Feng, J. et al. Activation of JAK2 catalytic activity requires phosphorylation of Y1007 in the kinase activation loop. Mol. Cell. Biol. (in the press).

11. Endo, T. A. et al. A new protein containing an SH2 domain that inhibits JAK kinases. Nature 387, $921-$ 924 (1997)

12. Rasko, J. E., Metcalf, D., Rossner, M. T., Begley, C. G. \& Nicola, N. A. The flt3/flk-2 ligand: receptor distribution and action on murine haemopoietic cell survival and proliferation. Leukemia 9, 20582066 (1995).

13. Smith, A., Metcalf, D. \& Nicola, N. A. Cytoplasmic domains of the common $\beta$-chain of the GM-CSF/ IL-3/IL-5 receptors that are required for inducing differentiation or clonal suppression in myeloid leukaemic cell lines. EMBO J. 16, 451-464 (1997).

14. Ihle, J. N. et al. Protein tyrosine phosphorylation in the regulation of hematopoiesis by receptors of the cytokine-receptor superfamily. Blood Cells 20, 65-80 (1994).

15. Yi, T., Mui, A. L., Krystal, G. \& Ihle, J. N. Hematopoietic cell phosphatase associates with the interleukin-3 (IL-3) receptor beta chain and down-regulates IL-3-induced tyrosine phosphorylation and mitogenesis. Mol. Cell. Biol. 13, 7577-7586 (1993).

16. Mui, A. L., Wakao, H., Kinoshita, T., Kitamura, T. \& Miyajima, A. Suppression of interleukin-3 induced gene expression by a C-terminal truncated Stat5: role of Stat5 in proliferation. EMBO J. 15, 2425-2423 (1996).

17. Quelle, F. W. et al. Erythropoietin induces activation of Stat5 through association with specific tyrosines on the receptor that are not required for a mitogenic response. Mol. Cell. Biol. 16, 1622-1631 (1996).

18. Hilton, D. J. et al. Cloning of a murine IL-11 receptor alpha-chain; requirement for gp 130 for high affinity binding and signal transduction. EMBO J. 13, 4765-4775 (1994).

19. Pearson, W. R. \& Lipman, D. J. Improved tools for biological sequence comparison. Proc. Natl Acad. Sci. USA 85, 2444-2448 (1988)

20. Pearson, W. R. Rapid and sensitive sequence comparison with FASTP and FASTA. Methods Enzymol. 183, 63-98 (1990)

21. Altschul, S. F., Gish, W., Miller, W., Myers, E. W. \& Lipman, D. J. Basic local alignment search tool. J. Mol. Biol. 215, 403-410 (1990).

22. Alexander, W. S., Metcalf, D. \& Dunn, A. R. Point mutations within a dimer interface homology domain of c-Mpl induce constitutive receptor activity and tumorigenicity. EMBO J. 14, 5569-5578 (1995).

23. Metcalf, D., Willson, T. A., Hilton, D. J., DiRago, L. \& Mifsud, S. Production of hematopoietic regulatory factors in cultures of adult and fetal mouse organs: measurement by specific bioassays. Leukaemia 9, 1556-1564 (1995).

24. Hilton, D. J., Watowich, S., Katz, L. \& Lodish, H. F. Saturation mutagenesis of the WSXWS motif of the erythropoietin receptor. J. Biol. Chem. 271, 4699-4708 (1996).

25. Nicola, N. A., Viney, E., Hilton, D. J., Roberts, B. \& Willson, T. Cloning of two novel transmembrane ligands for eph-related linases (LERKs) that are related to LERK2. Growth Factors 13, 141-149 (1996).

26. Novak, U. et al. Colony-stimulating factor 1-induced STAT1 and STAT3 activation is accompanied by phosphorylation of Tyk2 in macrophages and Tyk2 and JAK1 in fibroblasts. Blood 86, 2948-2956 (1995).

27. Naka, T. et al. Structure and function of a new STAT-induced STAT inhibitor. Nature 387, 924-929 (1997).
Acknowledgements. We thank R. Simpson and R. Moritz for recombinant mouse IL-6, C. McFarlane for help with production of recombinant cytokines, $S$. Cory for the PPGKpuropA vector, P. Lock for the pPGKneo vector and U. Novak for her generous advice regarding electrophoretic mobility shift assays. B. Roberts, D. Cary, L. Di Rago, S. Mifsud and N. Sprigg are thanked for their excellent technical assistance. D.J.H. was supported by a Queen Elizabeth II Postdoctoral Fellowship from the Australian Research Council. TJG is a senior research fellow of the NH\&MRC. This work was supported by the Anti-C

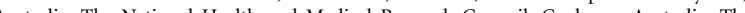
Australia, The National Heancil, Canberra, Australia, The J.D. and L. Harris Trust, the National Institutes of Health, Bethesda, Maryland and the Australian Federal Government Cooperative Research Centres Programme.

Correspondence and requests for materials should be addressed to D.J.H. (e-mail: hilton@wehi.edu.au).

\section{A new protein containing an SH2 domain that inhibits JAK kinases}

\section{Takaho A. Endo ${ }^{*}$, Masaaki Masuhara ${ }^{*}$, Masahiro Yokouchi ${ }^{\prime} \ddagger$, Ritsu Suzuki $¥ \neq$, Hiroshi Sakamoto*, Kaoru Mitsui ${ }^{\star}$, Akira Matsumoto*, Shyu Tanimura ${ }^{\star}$ Motoaki Ohtsubo*, Hiroyuki Misawa*, Tadaaki Miyazaki $\varsigma$, Nogueira Leonor $\$$, Tadatsugu Taniguchi $\varsigma$, Takashi Fujitall, Yuzuru Kanakurag, Seturo Komiya $\ddagger$ \\ \& Akihiko Yoshimura}

* Institute of Life Science, and $\ddagger$ Department of Orthopedic Surgery,

Kurume University, Aikawamachi 2432-3 Kurume 839, Japan

$\$$ Department of Immunology, Faculty of Medicine, University of Tokyo,

Bunkyo-ku, Tokyo 113, Japan

$\|$ Department of Tumor Cell Biology, The Tokyo Metropolitan Institute of Medical Science, Bunkyouku, Tokyo 113, Japan

Separtment of Hematology and Oncology, Osaka University Medical School, Suita 565, Japan

$\dagger$ These authors contributed equally to this work.

The proliferation and differentiation of cells of many lineages are regulated by secreted proteins known as cytokines. Cytokines exert their biological effect through binding to cell-surface receptors that are associated with one or more members of the JAK family of cytoplasmic tyrosine kinases. Cytokine-induced receptor dimerization leads to the activation of JAKs, rapid tyrosinephosphorylation of the cytoplasmic domains, and subsequent recruitment of various signalling proteins, including members of the STAT family of transcription factors, to the receptor complex ${ }^{1-5}$. Using the yeast two-hybrid system, we have now isolated a new $\mathrm{SH} 2$-domain-containing protein, $\mathrm{JAB}$, which is a JAK-binding protein that interacts with the Jak2 tyrosine-kinase JH1 domain ${ }^{6}$. JAB is structurally related to CIS, a cytokineinducible $\mathrm{SH} 2$ protein $^{7,8}$. Interaction of JAB with Jak1, Jak 2 or Jak3 markedly reduces their tyrosine-kinase activity and suppresses the tyrosine-phosphorylation and activation of STATs. $\mathrm{JAB}$ and CIS appear to function as negative regulators in the JAK signalling pathway.

We screened several yeast two-hybrid complementary DNA libraries and found a single positive clone, JAB, in a human B-cell library that could interact with the Jak2 JH1 domain (Fig. 1a-c). A database search revealed that the mouse and rat JAB genes are located downstream of the protamine gene cluster'. The coding region of the gene for mouse JAB appears to contain no introns, and encodes a 212-amino-acid protein. The JAB protein contains a central SH2 domain (amino acids 79-170) which is most closely related (35\% identical) to that of CIS, a cytokine-inducible SH2containing protein (Fig. 1d) that we have cloned previously ${ }^{7}$.

We examined the specificity of the interaction of JAB with the Jak2 JH1 domain using the yeast two-hybrid assay. We found no evidence for interaction of the Jak2 JH1 domain with other SH2containing proteins such as Crk, the $\mathrm{p} 85$ subunit of phosphatidylinositol-3-OH kinase (PI(3)K), phospholipase C- $\gamma$ (PLC $\gamma$ ) or a new 
SH2 protein, APS, although these proteins did interact with another tyrosine kinase, a D814V mutant ${ }^{10}$ oncogenic form of the $\mathrm{c}$-Kit cytoplasmic domain (Fig. 1a). CIS, the closest relative of JAB, did not interact with the Jak2 JH1 domain (Fig. 1b). Furthermore, tyrosine-kinase activity of Jak2 was required for interaction with $\mathrm{JAB}$ in yeast, because JAB did not interact with a kinase-defective mutant (K882D) of the Jak2 JH1 domain (Fig. 1c).

We confirmed that JAB bound to Jak2 in vitro using a recombinant fusion protein of glutathione- $S$-transferase with the JAB SH2 domain (GST-SH2). As shown in Fig. 2a (upper panel, $\alpha$ GST blot), GST-SH2, but not GST, bound to Jak2 immobilized on beads. The fusion protein of GST with the Jak2 JH1 domain (GST-JH1) bound to the JAB SH2 domain fused to maltose-binding protein (MBPSH2) immobilized on amylose resin but not to MBP alone (Fig. 2b, upper panel). ATP had little effect on the binding of Jak2 and GST$\mathrm{JH} 1$ to the JAB SH2 domain, probably because they were already heavily tyrosine-phosphorylated (Fig. 2a,b: $\alpha$ PY blot). These results indicate that the JAB SH2 domain binds directly to the tyrosinephosphorylated $\mathrm{JH} 1$ domain in vitro.

To confirm this interaction between JAK and JAB in intact cells, we co-expressed a Myc-epitope-tagged version of JAB (Myc-JAB) with Jak2 in 293 cells (Fig. 3 ). Jak2 was tyrosine-phosphorylated and active in the absence of cytokine stimulation in 293 cells because of its high level of production. The ability of antibodies against either the Myc epitope or Jak2 to precipitate a complex of JAK and JAB suggests that these two proteins interact in the cytoplasm (Fig. 3a,b). We noticed that tyrosine-phosphorylation of Jak2 was greatly reduced when it was co-expressed with JAB (Fig. 3c), suggesting that JAB inhibits tyrosine kinase activity upon binding to Jak2. Jak2 can be phosphorylated on several tyrosine residues, but phosphorylation of a single residue at Y1007 appears to be an early and critical requirement for catalytic activation ${ }^{11}$. We propose that JAB binds to Jak2 soon after Jak2 autophosphorylates Y1007, and blocks Jak2 kinase activity, thereby inhibiting further intra- and intermolecular phosphorylation.

To explore the downstream effects of the inhibition of Jak2 activity by JAB, we also expressed a physiological Jak2 substrate, Stat 3 , in 293 cells in the presence and absence of Jak2 and JAB (Fig. $3 d)$. A rise in Stat 3 phosphorylation was observed upon co-expression with Jak2. In the presence of JAB, however, there was a marked reduction in the level of tyrosine phosphorylation of Stat 3 , as well as Jak2 (Fig. 3d). Results were similar when Stat5 was used in place of Stat3 (data not shown). The specificity of the inhibition of Jak2 phosphorylation by JAB was suggested by the inability of the related molecule, CIS, to inhibit this Jak2 activation (Fig. 3e). The SH2 domain of JAB alone did not markedly inhibit the phosphorylation of Jak2, suggesting that the C-terminal or $\mathrm{N}$-terminal region is needed for the kinase-inhibitory activity of JAB (Fig. 3e). In 293 cells, JAB inhibited autophosphorylation of not only Jak2 but also of Jak1 and Jak3 (Fig. 3f), indicating that JAB may be a general inhibitor of JAK kinases. Although JAB bound to the active c-Kit kinase domain in yeast (Fig. 1a), JAB did not inhibit phosphorylation of either c-Kit (Fig. 3f) or the epidermal growth factor (EGF) receptor (data not shown), suggesting that the kinase-inhibitory action of JAB may be specific to JAK.

We investigated the effect of JAB on JAK-dependent gene activation in three different reporter-gene assay systems: Stat5 activation by erythropoietin $(\mathrm{EPO})^{8}$ (Fig. $\left.4 \mathrm{a}\right)$, Stat3 activation by interleukin (IL)-6 (ref. 12) (Fig. 4b), and c-fos promoter activation by IL-2 and IL-3 (ref. 13; Fig. 4c). Transient expression of JAB with the reporter gene inhibited reporter activation in response to both EPO and IL-6 (Fig. 4a,b). IL-2- and IL-3-induced c-fos promoter activation was
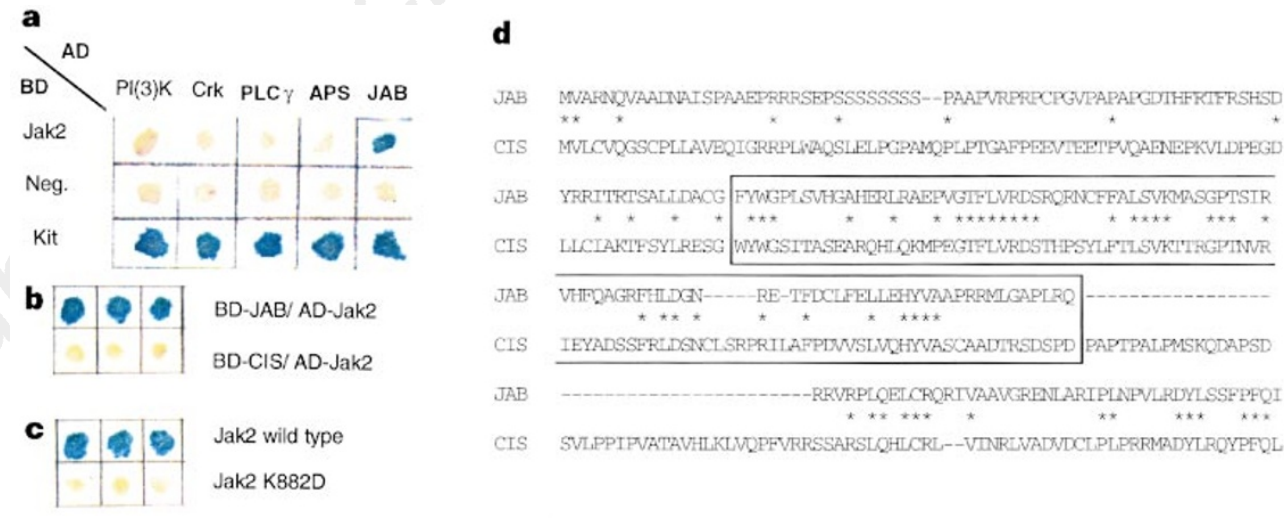

Figure 1 Two-hybrid analysis of Jak2 $\mathrm{JH} 1$ and JAB stained by in situ $\beta$ galactosidase assay (a-c) and sequence comparison between murine JAB and CIS (d). a, Yeast strains containing a LexA-binding domain (BD)-Jak2 JH1 fusion gene (Jak2), LexA BD alone (neg.), and BD-active c-Kit kinase domain (Kit) with the Gal4 activating domain (AD) fused to the $\mathrm{SH} 2$ domains from PI(3)Kp85, Crk, PLC- $\gamma$,
APS, or JAB. Dark blue staining indicates a positive interaction. b, Yeast strains (three independent colonies) containing either BD-JAB and AD-Jak2 JH1 or BDCIS (full-length) and AD-Jak2 JH1. c, Yeast strains containing either AD-JAB and BD-Jak2 JH1 (wild type), or BD-kinase-negative Jak2 JH1 (K882D). In d, asterisks indicate conserved amino acids. $\mathrm{SH} 2$ domains are boxed.

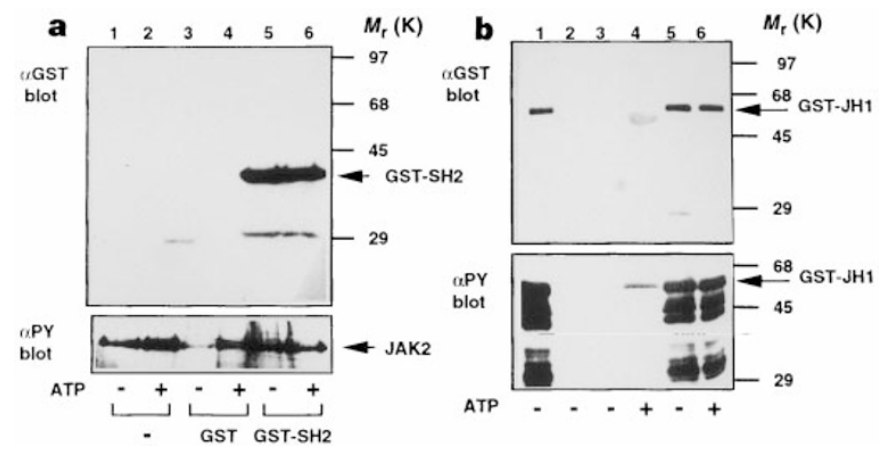

Figure 2 Interaction between Jak2 and JAB in vitro. a, Jak2-agarose was incubated with buffer alone (lanes 1, 2), GST (lanes 3, 4), or GST-JAB SH2-domain fusion protein (GST-SH2) (lanes 5,6 ) in the presence (+) or absence (-) of ATP. b, Immobilized MBP (lanes 2, 4) or MBP-SH2 (lanes 3, 5, 6) were incubated with (lanes 4-6) or without (lanes 2, 3) GST-JH1 in the presence (lanes 4 and 6) or absence (lane 5) of ATP. Lane 1, purified GST-JH1 fusion protein. Precipitates were analysed by immunoblotting with anti-GST ( $\alpha$ GST blot) and anti-PY ( $\alpha$ PY blot). 
almost completely inhibited by co-expression of full-length JAB (Fig. 4c). Although the c-fos gene may not be activated by STATs, the activation of JAKs is necessary for c-fos activation (see the effect of dominant-negative Jak3, J3M1, in Fig. 4c, and ref. 13). Thus, the decrease in c-fos activation in this assay therefore probably reflects inhibition of JAKs, rather than STATs, by JAB. Truncated JAB lacking both the $\mathrm{C}$ - and $\mathrm{N}$-terminal domains had little effect on IL-2- and IL-3-induced c-fos activation (Fig. 4c, Myc-SH2), indicating that these regions are necessary for full JAK kinase inhibition by JAB. This is consistent with the results shown in Fig. 3e, which indicate that the JAB SH2 domain alone is unable to inhibit JAK activation. Co-expression of JAB did not inhibit activation of the

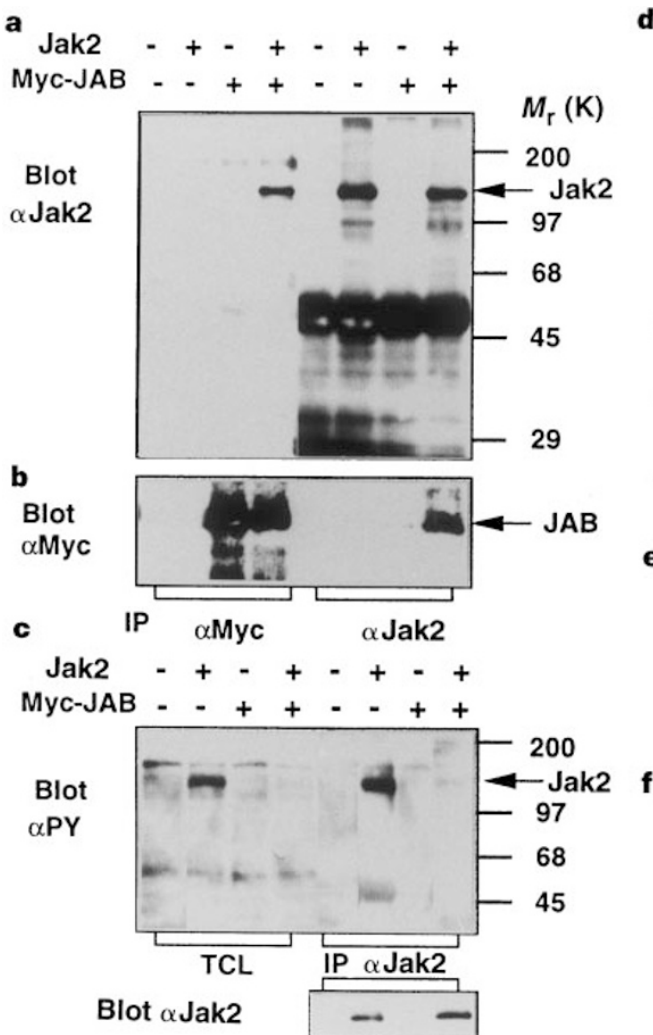

Figure 3 Association of Jak2 with JAB and inhibition of JAK kinase reaction in vivo. a-c, 293 cells were transfected with Jak2 and/or Myc-JAB constructs, and cell extracts were immunoprecipitated (IP) with antibodies specific for either Myc (IP $\alpha$ Myc) or Jak2 (IP $\alpha$ Jak2), then immunoblotted with anti-Jak2 (blot $\alpha$ Jak2) (a) or antiMyc (blot $\alpha$ Myc) (b) antibodies. c, Total cell extracts (TCL) or anti-Jak2 immunoprecipitates (IP $\alpha$ Jak2) were blotted with anti-PY (blot $\alpha$ PY) or anti-Jak2 (blot $\alpha$ Jak2). d, Jak2, Stat3 and JAB constructs were transiently transfected into 293

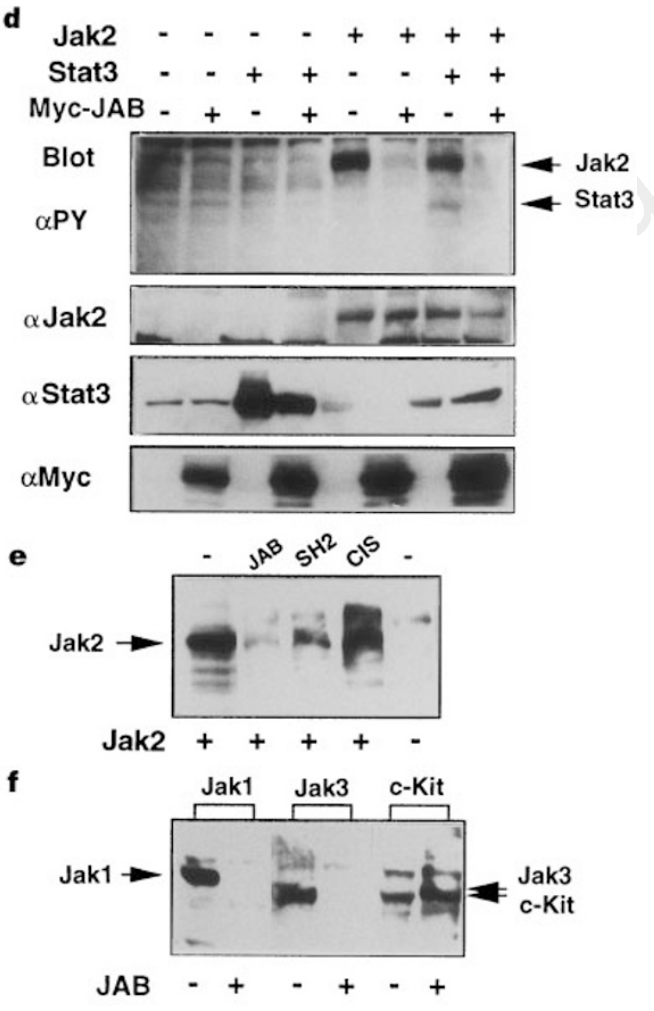

cells as indicated, and total cell extracts were blotted with anti-PY $(\alpha P Y)$, anti-Jak2 ( $\alpha$ Jak2), anti-Stat3 ( $\alpha$ Stat3), and anti-Myc ( $\alpha$ Myc) antibodies. e, 293 cells were transfected with the Jak2 (constructs) (+) or vector (-), either alone or with pcDNA3 carrying full-length JAB (JAB), JAB SH2 domain (SH2), or full-length $\mathrm{CIS}$ (CIS). Cell extracts were immunoblotted with anti-PY. f, 293 transfected with Jak1, Jak3 or cKit(D814V) constructs, either alone (-) or with (+) pcDNA3-Myc JAB. Cell extracts were immunoblotted with anti-PY.
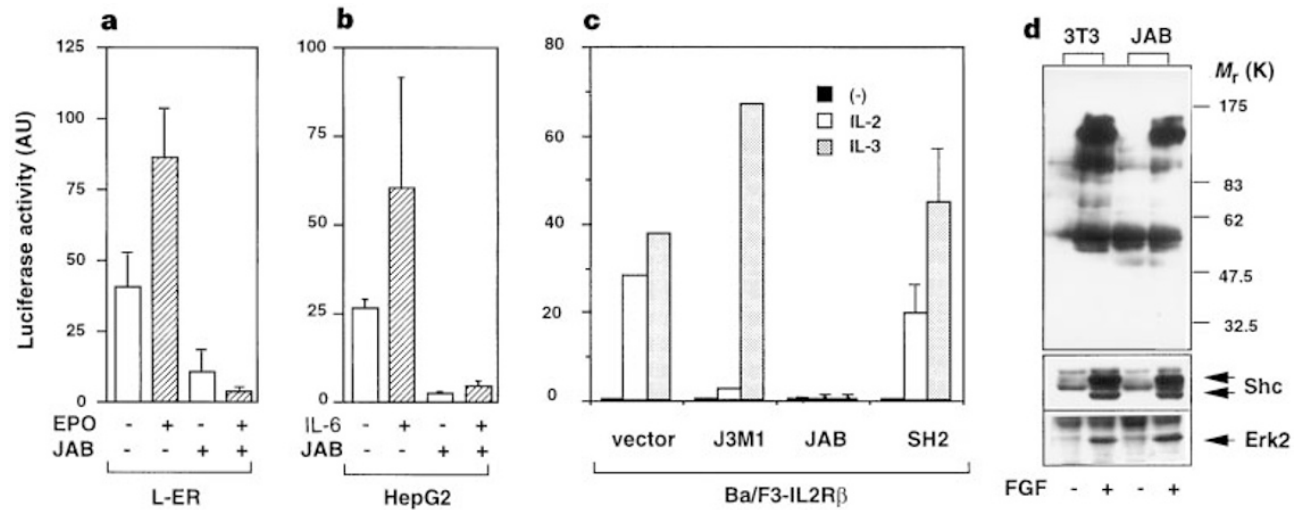

Figure 4 Inhibition of JAK activity by JAB in cells assessed by reporter assay. The indicated cells were transfected with reporter genes for Stat5 (a), Stat3 (b) or c-fos promoter (c) with pcDNA3 carrying JAB (+ or JAB), the SH2 domain of JAB (SH2), $\mathrm{JH} 1$-truncated Jak3 (J3M1), or vector alone (-). Luciferase activity (AU, arbitrary units) was measured after stimulation without (-) or with (+) 10 unit m$^{-1}$ EPO (a),
$20 \mathrm{ng} \mathrm{ml}^{-1} \mathrm{IL}-6$ (b), or either $0.5 \mathrm{nM} \mathrm{IL-2}$ or IL-3 (c), for 10-12 h. In d, parental NIH3T3 cells and 3T3 cells expressing Myc-JAB (JAB) were stimulated for 10 min either with (+) or without (-) $500 \mathrm{ng} \mathrm{m}^{-1}$ FGF. Total cell lysates (upper panel) or anti-Shc or anti-MAP kinase (Erk2) immunoprecipitates (lower panels) were blotted with antiPY antibody. 
c-fos promoter stimulated by cyclic AMP (data not shown), suggesting that $\mathrm{JAB}$ does not inhibit any pathways other than those involving JAKs. Furthermore, constitutive overexpression of JAB in NIH3T3 cells did not inhibit basic fibroblast growth factor (FGF)-induced tyrosine-phosphorylation of cellular proteins, including Shc and Erk2 (Fig. 4d), whereas interferon- $\alpha$-induced antiviral and antiproliferative effects were almost completely blocked in the JAB transformants (data not shown).

We have described the cloning of a cDNA encoding a protein that binds to the catalytic domain of the cytoplasmic tyrosine kinase Jak2. Our results indicate that interaction with JAB inhibits the catalytic activity of JAKs and thus the activation of signalling intermediates such as STATs. CIS also inhibits cytokine signal transduction by competing with Stat 5 or other signalling molecules for docking sites on the receptor ${ }^{7,8}$. The potent inhibition by JAB and CIS of cytokine activity suggests that members of this family may be key regulators of haematopoiesis, of the response to infection and injury, and of development-all biological processes in which JAKs and STATs are important.

Note added in proof: Elsewhere in this issue, JAK inhibitors similar to JAB are reported under the names $\mathrm{SOCS}^{18}$ and SSI-1 (ref. 19).

\section{Methods}

Two-hybrid screening and cloning of JAB. The two-hybrid screen was done according to ref. 14. The hybrid bait consisted of the Jak2 JH1 domain, and the DNA-binding/dimerization domain of LexA allowed interchain tyrosine phosphorylation of the kinase domain in yeast. The murine Jak2 JH1 domain (amino acids 839-1,127; kindly provided by R. Fukunaga) or the oncogenic cKit kinase domain (amino acids 544-975, containing the D814V mutation ${ }^{10}$ ) in a pBTM116 vector was transfected into yeast strain L40. Kinase-negative JH1 was created by substitution of lysine $(\mathrm{K})$ at position 882 to aspartic acid (D) as described ${ }^{15}$. A human B-lymphocyte cDNA library in a pACT vector ${ }^{16}$ was screened.

Binding of JAB to Jak2 in vitro. About $1 \mu \mathrm{g}$ purified Jak2 (Upstate Biotechnology) was incubated with $1 \mu \mathrm{g}$ purified GST or GST-SH2 fusion protein (amino acids $78-180$ of human JAB) in kinase buffer (50 mM HEPES, pH 7.5, $50 \mathrm{mM} \mathrm{NaCl}, 5 \mathrm{mM} \mathrm{MgCl}_{2}, 5 \mathrm{mM} \mathrm{MnCl}_{2}$ and $0.1 \mathrm{mM} \mathrm{Na}_{3} \mathrm{VO}_{4}$ ) in the presence or absence of $0.2 \mathrm{mM}$ ATP for $2 \mathrm{~h}$ at room temperature. After washing twice with phosphate-buffered saline, protein bound to beads was analysed by immunoblotting with anti-phosphotyrosine (PY) (4G10) or goat anti-GST (Pharmacia).

Analysis of JAB / Jak2 interaction in intact cells. Jak2 cDNA in the expression vector pEF-BOS and Myc-epitope-tagged-JAB (Myc-JAB; ref. 17) in pcDNA3 $(2.5 \mu \mathrm{g}$ per transfection) were transiently expressed in 293 cells grown in $35-$ $\mathrm{mm}$ dishes using calcium phosphate co-precipitation. Cell extracts were immunoprecipitated with either monoclonal anti-Myc antibody (9E10) or polyclonal anti-Jak2 antibody as described ${ }^{7}$. Total cell lysate $(50 \mu \mathrm{g}$ protein) or the immune complex were further analysed by immunoblotting with anti-PY, anti-Myc, and anti-Jak2. For phosphorylation of Jak1 and Jak3, 293 cells were transfected with $2.5 \mu \mathrm{g} \mathrm{Jak1} \mathrm{in} \mathrm{pCDM8} \mathrm{(from} \mathrm{A.} \mathrm{F.} \mathrm{Wilks),} \mathrm{or} \mathrm{with} \mathrm{Jak3} \mathrm{in} \mathrm{pSR} \alpha$ (from T. Shirasawa), or with murine oncogenic c-Kit carrying the D814V mutation in pEF-BOS ${ }^{10}$ in the presence or absence of $2.5 \mu \mathrm{g} \mathrm{JAB} \mathrm{cDNA.}$

Reporter gene assay. Luciferase gene constructs containing an EPO/Stat5responsive promoter from the CIS gene ${ }^{8}$, an IL-6/Stat3-responsive promoter (based on the acute phase response element ${ }^{12}$, or the c-fos promoter ${ }^{13}$, were transfected into L929 cells expressing the EPO receptor (L-ER), the hepatocyte cell line HepG2, or into Ba/F3 cells expressing the IL-2 receptor $\beta$-chain $(\mathrm{Ba} / \mathrm{F} 3$ IL2R $\beta$ ), respectively. Luciferase activity was measured as described ${ }^{8}$.

Received 17 March; accepted 2 May 1997.

Miyajima, A., Kitamura, T., Harada, N., Yokota, T. \& Arai, K. Cytokine receptors and signal transduction. Annu. Rev. Immunol. 10, 295-331 (1992).

2. Schindler, C. \& Darnell, J. E. Jr Transcriptional responses to polypeptide ligands: the JAK-STAT pathway. Annu. Rev. Biochem. 64, 621-651 (1995).

Ihle, J. N. Cytokine receptor signalling. Nature 377, 591-594 (1995).

4. Ihle, J. N. STATs: Signal transducers and activators of transcription. Cell 84, 331-334 (1996).

5. Darnell, J. E. J., Kerr, I. M. \& Stark, G. R. Jak-STAT pathways and transcriptional activation in response to IFNs and other extracellular signaling proteins. Science 264, 1415-1421 (1994).
6. Harpur, A. G., Andres, A. C., Ziemiecki, A., Aston, R. R. \& Wilks, A. F. JAK2, a third member of the JAK family of protein tyrosine kinases. Oncogene 7, 1347-1353 (1992).

7. Yoshimura, A. et al. A novel cytokine-inducible gene CIS encodes an $\mathrm{SH} 2$-containing protein that binds to tyrosine-phosphorylated interleukin-3 and erythropoietin receptors. EMBO J. 14, 28162816 (1995)

8. Matsumoto, A. et al. CIS, a cytokine inducible $\mathrm{SH} 2$ protein, is a target of the JAK-STAT5 pathway and modulates STAT5 activation. Blood 89, 3148-3154 (1997).

9. Schluter, G. et al. Sequence analysis of the conserved protamine gene cluster shows that it contains a fourth expressed gene. Mol. Reprod. Dvelop. 43, 1-6 (1996).

10. Kitayama, H. et al. Constitutively activating mutations of c-kit receptor tyrosine kinase confer factorindependent growth and tumorigenicity of factor-dependent hematopoietic cell lines. Blood 85, 790798 (1995).

11. Feng, J. et al. Activation of JAK2 catalytic activity requires phosphorylation of Y1007 in the kinase activation loop. Mol. Cell. Biol. 17, 2497-2501 (1997).

12. Nakajima, K. et al. A central role for Stat3 in IL-6-induced regulation of growth and differentiation in M1 leukemia cells. EMBO J. 15, 3651-3658 (1996)

13. Kawahara, A., Minami, Y., Miyazaki, T., Ihle, J. N. \& Taniguchi, T. Critical role of the interleukin 2 (IL2) receptor gamma-chain-associated Jak3 in the IL2-induced c-fos and c-myc, but not $b c l$-2, gene induction. Proc. Natl Acad. Sci. USA 92, 8721-8728 (1995).

14. Vojtek, A. B., Hollenberg, S. M. \& Cooper, J. A. Mammalian Ras interacts directly with serine/ threonine kinase Raf. Cell 74, 205-214 (1993).

15. Briscoe, J. et al. Kinase-negative mutants of JAK1 can sustain interferon- $\gamma$-inducible gene expression but not an antiviral state. EMBO J. 15, 799-809 (1996).

16. Harper, J. W., Adami, G. R., Wei, N., Keyomarsi, K. \& Elledge, S. J. The p21 Cdk-interacting protein Cipl is a potent inhibitor of G1 cyclin-dependent kinase. Cell 75, 805-816 (1993).

17. Turner, D. L. \& Weintraub, H. Expression of achaete-scute homolog 3 in Xenopus embryos converts ectodermal cells to a neural fate. Genes Dev. 8, 1434-1447 (1994).

18. Starr, R. et al. A family of cytokine-inducible inhibitors of signalling. Nature 387, 917-921 (1997).

19. Naka, T. et al. Structure and function of a new STAT-induced STAT inhibitor. Nature 387, 924-929 (1997).

Acknowledgements. We thank $\mathrm{H}$. Ohgusu for technical assistance, T. Hirano for the APRE/jun promoter construct and STAT3 cDNA, R. Fukunaga for Jak2, A. F. Wilks for the Jak1, T. Shirasawa for rat Jak 3 CDNAs, and D. Hilton and R. Starr for reading and editing the manuscript. Part of this work was Kowa Life Scince Found the Kowa Life Science Foundation, the Motida Memorial Science Foundation and the Naito Memorial Foundation.

Correspondence and requests for materials should be addressed to A.Y. (yosimura@lsi.kurume-u.ac.jp). The nucleotide sequence data reported here will appear in the DDBJ, EMBL and GenBank nucleotide sequence databases under accession numbers $\mathrm{AB} 000676$ (human JAB) and $\mathrm{AB} 000677$ (mouse JAB)

\section{Structure and function of a new STAT-induced STAT inhibitor}

\section{Tetsuji Naka*, Masashi Narazaki ${ }^{\star}$, Moritoshi Hirata*, Tomoshige Matsumoto*, Seijiro Minamoto*, Atsufumi Aono*, Norihiro Nishimoto $\nmid$, Tadahiro Kajita $\ddagger$ Tetsuya Taga $\$$, Kazuyuki Yoshizaki $\dagger$, Shizuo Akirall \& Tadamitsu Kishimoto*}

* Osaka University Medical School Department of Medicine III. 2-2, Yamada-Oka, Suita, Osaka 565, Japan

$\dagger$ Medical Science I, School of Health and Sports Sciences, Department of Osaka University. 2-1, Yamada-Oka, Suita, Osaka 565, Japan

$\ddagger$ Research and Development Center, International Reagents Corporation,

1-2, 1-Chome, Murotani, Nishiku, Kobe 651-22, Japan

$\$$ Department of Molecular Cell Biology, Medical Research Institute,

Tokyo Medical and Dental University. 2-3-10, Kanda-Surugadai, Chiyoda-ku, Tokyo 101, Japan

II Department of Biochemistry Hyogo College of Medicine, 1-1, Mukogawa, Nishinomiya, Hyogo 663, Japan

The signalling pathway that comprises JAK kinases and STAT proteins (for signal transducer and activator of transcription) is important for relaying signals from various cytokines outside the cell to the inside ${ }^{1-3}$. The feedback mechanism responsible for switching off the cytokine signal has not been elucidated. We now report the cloning and characterization of an inhibitor of STAT activation which we name SSI-1 (for STAT-induced STAT inhibitor-1). We found that SSI-1 messenger RNA was induced by the cytokines interleukins 4 and 6 (IL-4, IL-6), leukaemiainhibitory factor (LIF), and granulocyte colony-stimulating factor (G-CSF). Stimulation by IL-6 or LIF of murine myeloid leukaemia cells (M1 cells) induced SSI-1 mRNA expression which was blocked by transfection of a dominant-negative mutant of Stat3, 